\title{
Health Journalism Internships: A Social Marketing Strategy to Address Health Disparities
}

\author{
Duy H. Nguyen • Suzuho Shimasaki • \\ Helen Shi Stafford • Georgia Robins Sadler
}

Received: 30 September 2009 /Revised: 21 December 2009/Accepted: 22 January 2010 / Published online: 26 February 2010

(C) The Author(s) 2010. This article is published with open access at Springerlink.com

\begin{abstract}
The USA seeks to eliminate health disparities by stimulating the rapid uptake of health-promoting behaviors within disadvantaged communities. A health journalism internship incorporates social marketing strategies to increase communities' access to cancer information, while helping the interns who are recruited from underrepresented communities gain admission to top graduate schools. Interns are taught basic health journalism skills that enable them to create immediate streams of cancer-related press releases for submission to community newspapers. Interns are charged
\end{abstract}

D. H. Nguyen • S. Shimasaki • H. S. Stafford • G. R. Sadler $(\bowtie)$ Rebecca and John Moores UCSD Cancer Center,

University of California, San Diego,

3855 Health Sciences Drive,

La Jolla, CA 92093-0850, USA

e-mail: gsadler@ucsd.edu

G. R. Sadler

Department of Surgery/Division of General Surgery,

University of California, San Diego School of Medicine,

La Jolla, CA, USA

S. Shimasaki

University of California, Los Angeles School of Public Health,

Los Angeles, CA, USA

D. H. Nguyen • H. S. Stafford

University of California, San Diego School of Medicine,

La Jolla, CA, USA

H. S. Stafford

Sam and Rose Stein Institute for Research on Aging,

University of California, San Diego,

La Jolla, CA, USA

G. R. Sadler

SDSU/UCSD Joint Doctoral Program in Clinical Psychology,

San Diego, CA, USA with the social responsibility of continuing this dissemination process throughout their careers. Intermediate outcomes are measured as mediators of distal behavioral change goals.

Keywords Asian · Communications · Health Journalism . Health disparities $\cdot$ Hispanic $\cdot$ Social marketing .

Targeted media

\section{Introduction}

Healthy People 2010 and 2020 address the need to resolve the many well-documented health disparities that exist in the USA among African Americans [1-3], Asian Americans [4, 5], Hispanic Americans [6, 7], Native Americans $[8,9]$, American Pacific Islanders [10, 11], the Deaf and hard of hearing $[12,13]$, and many other communities. Virtually all of the most popular theoretical models, developed to frame cancer control intervention programs, recognize the key role that access to information plays in reducing health disparities [14-19].

Social scientists, such as Andreasen [20] and Kotler et al. [21], showed that traditional marketing strategies could be adapted to spread information to promote beneficial social change, thereby launching the field of social marketing. These early social marketing innovations focused mainly on the purchase of expensive mass media to disseminate social messages [22]. While mass media does indeed reach the masses, public health researchers have shown that focused media efforts are more effective in reaching smaller audiences where language and cultural barriers hinder health communication [23-25].

More recent marketing authorities recommend the adoption of strategies that have greater credibility, relevance, sustainability, effectiveness, and lower costs to accommodate smaller 
marketing budgets [26, 27], as well as messages with greater linguistic and cultural competency needed to gain the attention of target audiences [28-31]. Guerilla marketing, viral marketing, permission marketing, buzz marketing, wordof-mouth marketing, and earned media promotion are among the newer marketing tools being promoted [32]. Community newspapers, social networking, ezines, and other Internet strategies for disseminating information have expanded the effective options available to social marketers while significantly decreasing their costs. Gladwell examined social change to discover why some social changes took on the characteristics and proportions of an epidemic, while others languished. He identified critical and reproducible elements in the spread of information that led to most epidemic-like social shifts: the involvement of the right personalities disseminating a "sticky" message in an environment that supported the adoption of the message [33].

This paper describes a health journalism internship (HJI) designed to increase minority communities' access to health information by amplifying the "stickiness factor" of the health messages. In contrast with generic health information delivered in mainstream media, this internship trained minority university students to create press releases in which the content was personalized to reflect its relevance for the target community. To measure the internship's impact and each intern's contributions, a universal scoring rubric was also developed that can be applied across communities and may be useful to other research studies.

\section{Description of the Health Journalism Internship}

To create low-cost and sustainable streams of credible, accurate, and timely cancer-related press releases to attract free media attention, a HJI was created in 1994 as a partnership between Moores University of California, San Diego (UCSD) Cancer Center's Community Outreach Program and UCSD's service learning programs. In conceptualizing the HJI, university students would be recruited from underrepresented communities and taught how to make cancer-related press releases relevant to their community. To assure a steady stream of interns from diverse cultural backgrounds, the HJI director used the university's public service announcement network, flyers, and word-of-mouth.

Curriculum of HJI The HJI has reading and writing assignments equivalent to other university courses. The course syllabus includes reading assignments drawn from media research [34-38], public health research [39, 40], and lay marketing $[27,32,41-50]$, which teach interns how to:

1. Access sources of information on embargoed scientific articles [50] and conduct advanced literature searches to discover timely scientific topics of potential interest to readers $[49,50]$;

2. Prepare press releases for principal investigators of institutional review board (IRB)-approved research studies that help raise the community's scientific literacy while recruiting study participants (IRB approval required for study-specific press releases);

3. Prepare press releases on topics that would not normally trigger public interest, e.g., an article promoting colonoscopy;

4. Use cancer registry data to demonstrate how basic or clinical science discoveries could reduce a health disparity; and

5. Develop positive attitudes towards writing and belief in interns' capacities to make an important contribution to society.

Students select a topic, outline a draft press release, and review it with the faculty before proceeding to prepare the full article. Interns are asked to write at a literacy level appropriate for lay readers and integrate one or more of the common behavioral theoretical frameworks. Interns electronically submit their faculty-approved article to community newspapers along with a byline describing their HJI, plus the names and contact information of the sponsoring faculty and institution. A letter from the faculty member to the editor is included to assure that the article receives appropriate attention. Finally, interns contact the editors to confirm that the article has been received, and is under active review. For larger institutions, such as universities, collaboration from public information officers is mandatory. As trust is built from the supervising faculty's vigilant oversight to assure high-quality press releases, this requirement for institutional review of interns' press releases may be relaxed.

Writing Teams Interns work in writing circles, where they critique each other's work to improve their skills. They also create new versions of the original article, culturally honing them to assure applicability for other communities and making them relevant for each community newspaper's readers.

Translations for Diverse Communities A unique advantage of recruiting interns from various cultural backgrounds is that many have the linguistic proficiency to translate English language press releases into other languages. By working in language teams, the translations can be well refined before they are sent to linguistic authorities for final approval. Consequently, a single press release has the potential to reach multiple communities and multiple linguistic sub-groups within a particular community. This interactive environment is modeled to show students how 
they can sustain and amplify their community-focused, educational writing activities as a lifelong professional commitment.

\section{Developing an Instrument to Measure the Impact of the HJI}

Measuring media's impact is challenging [51]. It is often not economically feasible to track the long-term behavioral impact of media promotions. The stages of change model highlights another measurement challenge: behavioral change is a series of smaller changes from the precontemplation stage to the maintenance stage [15]. Paralleling this model, in marketing, it is expected that between seven and 21 messages need to be received before the desired action is likely to be triggered. Thus for the HJI, it is difficult to identify the value of one article since it would likely only help to move the reader slightly through the stages of change, rather than being solely responsible for the change. Other impact measures are therefore needed; for example, the number of patients recruited to a research study exclusively through one article or the willingness of the study's principal investigator to continue collaborating with the interns on future publications.

For this HJI, a more robust outcome measure was sought that would make it possible to track the impact of the HJI quantitatively over time, by media source, and among interns. Initially, the authors considered the basic outcome measure of counting the total number of articles published and the number of articles by topic. For example, over 80 articles are known to have been published from the Moores UCSD Cancer Center's HJI. These were on topics chosen for their importance to cancer control efforts and written with a cancer control focus determined by the Cancer Center. Common topics were breast cancer (35), prostate and cervical cancer (12), and cancer survivorship and pain management (10).

News articles have unique characteristics that can differentially impact readers (Fig. 1). The most significant distinguishing characteristic is whether the media publication is "purchased" or "earned." Purchased media's value is concrete; it is the cost of purchasing a specific amount of space, at a specific time, and at a specific site. Earned media, in contrast, costs nothing, but is deemed to have far greater impact value on the reader than purchased media, because virtually anyone can purchase media space. Earned media is also considered relatively unbiased by readers. The public perceives that the article has been vetted by an independent authority and deemed worthy of public dissemination.

The common elements between earned and purchased media make it possible to set a baseline value on the earned media by using the same attributes that are used to set
Attributed Value of a characteristic $=(\#$ of column inches $) X(\$ 20 /$ column inch cost) X (Added Incremental Value*)

\begin{tabular}{|c|c|c|c|}
\hline $\begin{array}{l}\text { Characteristics of a } 40 \text {-column inch article } \\
\text { with a cost basis of } \$ 20 / \text { column inch }\end{array}$ & $\begin{array}{l}\text { Column } \\
\text { Inches } \\
\text { Printed }\end{array}$ & $\begin{array}{c}\text { Added } \\
\text { Incremental } \\
\text { Value* }\end{array}$ & $\begin{array}{l}\text { Attributed } \\
\text { Value }\end{array}$ \\
\hline \multicolumn{4}{|l|}{ Location } \\
\hline$\overline{\text { Front page of newspaper }}$ & 20 & $50 \%$ & 200 \\
\hline Inside front page of newspaper & 20 & $20 \%$ & 80 \\
\hline Back page of newspaper & 0 & $20 \%$ & 0 \\
\hline Front page of newspaper section & 0 & $25 \%$ & 0 \\
\hline Inside front page of newspaper section & 0 & $15 \%$ & 0 \\
\hline Back page of newspaper section & 0 & $15 \%$ & 0 \\
\hline \multicolumn{4}{|l|}{ Visual Draw } \\
\hline Above the horizontal fold & 15 & $20 \%$ & 60 \\
\hline Outer columns & 40 & $20 \%$ & 160 \\
\hline \multicolumn{4}{|l|}{ Enhancements } \\
\hline Accompanying photo(s) & 10 & $25 \%$ & 50 \\
\hline Accompanying graphic(s) & 0 & $25 \%$ & 0 \\
\hline Accompanying pullouts & 4 & $15 \%$ & 12 \\
\hline Color photos or graphics & 12 & $25 \%$ & 60 \\
\hline \multicolumn{4}{|l|}{ Geographic Distribution } \\
\hline \multicolumn{4}{|l|}{ Radius of geographic distribution } \\
\hline$<10$ miles & & $0 \%$ & \\
\hline $10-25$ miles & 40 & $10 \%$ & 80 \\
\hline$>25$ miles & & $20 \%$ & \\
\hline \multicolumn{4}{|l|}{ Or distribution in multiple locations } \\
\hline 1 county/region & & $0 \%$ & \\
\hline $2-5$ counties/regions & 40 & $30 \%$ & 240 \\
\hline$\geq 6$ counties/regions & & $50 \%$ & \\
\hline \multicolumn{4}{|l|}{$\underline{\text { Readership }}$} \\
\hline \multicolumn{4}{|l|}{ Primary readership } \\
\hline$<10,000$ & & $0 \%$ & \\
\hline $10,000-25,000$ & 40 & $5 \%$ & 40 \\
\hline$>25,000$ & & $10 \%$ & \\
\hline \multicolumn{4}{|l|}{ And secondary readership } \\
\hline$<50,000$ & & $0 \%$ & \\
\hline $50,000-200,000$ & 40 & $5 \%$ & 40 \\
\hline$>200,000$ & & $10 \%$ & \\
\hline \multicolumn{4}{|l|}{ Other Impact Factors } \\
\hline \multicolumn{4}{|l|}{ Earned advertising income } \\
\hline$<\$ 5,000 /$ month & & $0 \%$ & \\
\hline$\$ 5,000-\$ 10,000 /$ month & 40 & $5 \%$ & 40 \\
\hline$>\$ 10,000 /$ month & & $10 \%$ & \\
\hline \multicolumn{4}{|l|}{ Frequency of publication } \\
\hline$>$ Monthly & & $0 \%$ & \\
\hline Monthly & & $5 \%$ & \\
\hline Weekly & 40 & $10 \%$ & 80 \\
\hline Daily & & $15 \%$ & \\
\hline \multicolumn{4}{|l|}{ Number of media partners } \\
\hline None & & $0 \%$ & \\
\hline $1-5$ & 40 & $10 \%$ & 80 \\
\hline$>6$ & & $20 \%$ & \\
\hline $\begin{array}{l}\text { Online access to articles } \\
\text { Incremental Value of "Earned" (vs. Bought) }\end{array}$ & 40 & $50 \%$ & 400 \\
\hline Print Media & 40 & $100 \%$ & 800 \\
\hline \multicolumn{4}{|l|}{ Triggers Measured } \\
\hline Triggered TV attention & 40 & $50 \%$ & 400 \\
\hline Triggered radio attention & 40 & $50 \%$ & 400 \\
\hline $\begin{array}{l}\text { Triggered more print attention, e.g., letter to } \\
\text { editor }\end{array}$ & 40 & Varies & \\
\hline $\begin{array}{l}\text { Triggered contact with the agency, e.g., phone } \\
\text { calls, visits, coupon use, etc. }\end{array}$ & 40 & Varies & \\
\hline \multicolumn{3}{|l|}{ Total score for the 40-column inch article } & 4022 \\
\hline
\end{tabular}

Fig. 1 Example of a scoring rubric to derive quantitative valuations of earned print media. In this example, the scoring rubric is used to calculate the value of earned print media for a 40-column inch article that was printed in a weekly community newspaper that charged $\$ 20 /$ column inch of advertisement (i.e., $\$ 800$ for 40 column inches, so the number of 800 was chosen as the base value). The characteristics of the newspaper include: (1) geographic distribution radius of 20 miles, (2) distribution to three other counties/regions, (3) a primary readership of 15,000 and a secondary readership of $75,000,(4)$ an income from advertisement of $\$ 10,000 /$ month, (5) in a partnership with three other cooperating media outlets, and (6) electronic distribution. The article was printed in the outer columns of the front and back pages of the newspaper, with a small section placed above the fold. The article had one accompanying color photograph and one small pullout. 
prices for purchased media (Fig. 1). The article's placement (section, page number, and exact location on the page) and enhancements (bolded pullouts and accompanying photographs) can add a premium value to the article by increasing the likelihood of drawing readers' attention to the article. For articles that carry embedded calls-to-actions (e.g., "Call for our brochure" or "Bring this coupon for half price admission to our health fair"), another way of placing value on the article is the number of responses it triggers.

Additionally, newspapers have publication-related properties that carry incremental values of impact on readers, e.g., scopes of geographic distribution, circulation rates, primary readerships, secondary readerships, advertising incomes, frequencies of publication, and partnerships with other media outlets. Figure 1 offers an example of how all of these elements can be incorporated into a universal scoring rubric, which can be used consistently to derive a numerical value for each earned-media article, calculate the cumulative impact of the HJI over time, and make comparisons by media sources, interns, and other considerations.

Unlike manuscripts that are submitted to peer-reviewed journals, HJI press releases can, and should, be submitted simultaneously to as many community newspapers as possible to produce multiple publications in unique media sources and a synergistic community impact. The value of each of these published articles should be calculated, because they create value by reaching more readers or reinforcing the message through repeated delivery to the same reader.

Some media outlets are part of publishing conglomerates, which circulate articles within their networks. This creates the challenge of tracking all publications of each article as they wend their ways through the subsidiary partners, making it easy to underestimate the true breadth of the dissemination. Another tracking challenge when evaluating HJI articles occurs when articles are considered "evergreen" by editors, i.e., relevant for publishing or republishing at any time to fill print voids. Thus, to evaluate the HJI's true value, it is important to make an assessment of an article's value each time it is published.

\section{Discussion}

In public health programs, mass media has been shown to be a cost-effective strategy for increasing the public's knowledge of cancer-related information, but has been less effective as a strategy to reach underserved communities [23]. In contrast, the use of targeted print media has been shown to be an effective strategy in disseminating health information to disadvantaged ethnic minorities $[23,25,52,53]$.

In this HJI, the interns' cancer-related press releases were consistently published by newspapers of local ethnic communities, facilitating the dissemination of important health messages to hard-to-reach communities. Although the impact of this intervention on public behavior was not evaluated by this demonstration project, several important quantitative and qualitative observations could be made about the promising values of the HJI.

The HJI's positive contributions to the underserved communities were strongly reflected in the newspaper editors' enthusiastic acceptance and promotion of the interns' press releases. Virtually all of the newspapers in this demonstration study became permanent HJI partners, a relationship that facilitated the publication of subsequent articles and also indicated the HJI's potential to be a sustainable and cost-effective cancer education strategy for underserved communities.

Due to the long shelf life and circulatory properties of newspaper articles, the journalistic products of the HJI have the potential to reach underserved communities in manners that are unique to print media. First, since many newspapers of ethnic communities are provided at either no- or low-cost and distributed at high-traffic gathering places, such as supermarkets, the articles are widely available and easily accessible to members of the communities. Further, readers can easily clip articles for their own use or to pass on to relatives and friends. Second, the articles are printed with the author's contact information, the sponsoring institution and faculty, and governmental and scientific sources of information. This provides readers with the means to obtain more information if desired. Third, other trusted media sources, such as television and radio programs, may discuss news articles, thereby furthering the information's dissemination.

The benefits of the HJI to the interns are numerous. The HJI is an opportunity for students to gain practical knowledge and skills in both scientific and media fields. It provides interns insights into how people's cultural, ethnic, social, economic, and genetic backgrounds can influence their health and their community's health, and how these factors can contribute to health disparities. The HJI helps interns grasp the issues underlying social challenges, advance their problem solving skills, and advocate for healthier communities, while strengthening their communication skills $[54,55]$. Ultimately, it is anticipated that the interns will develop a lifelong interest in creating articles that turn complex health and science information into easily accessible and applicable information for their community. Lastly, the HJI is a valuable mentorship from which interns may receive timely career advice and unique letters of recommendation that strengthen their applications for admission to top graduate and professional schools.

The HJI is also a good learning experience for the researchers with whom the interns collaborate. Few have ever considered this approach for disseminating their field's life-saving information to hard-to-reach communities or as a means to increase participation of members of underrep- 
resented communities in research studies. The HJI is a model they can replicate with their own staff and students.

Finally, the scoring rubric developed to assess the impact of the HJI can become an excellent resource for evaluating other related projects and media studies on health disparities. The measurement device may be particularly applicable to studies that compare the quality of the same print information across different newspapers [56]. By giving a numerical score to a body of print information based on its characteristics in a newspaper, the relevance of that information may be measured.

In spite of its promises, the HJI has several limitations health educators will need to balance. Since it relies on volunteer interns, cancer educators may not be able to produce articles on a timely basis. Educators will not have control over when the articles are published. Finally, errors may occur in the translation of the English language version for non-English language newspapers. Here, the least expensive solution may be for the faculty member to recruit the assistance of faculty colleagues and community leaders who have high language proficiency and share the faculty member's passion for social justice and advocacy.

\section{Conclusion}

It is too soon to assess whether interns become lifelong advocacy journalists as a result of the HJI, and it is difficult to separate out the degree to which this educational effort contributes to improving community well-being over time. However, given the relatively low cost of conducting such a program and the potential gains for the communities and the interns, there appears to be sufficient justification to encourage other universities and health institutions to replicate this internship.

Acknowledgments This study was funded by: the National Cancer Institute Grants R25 CA65745; P30 CA023100; 1U54CA132379 and 1U54CA132384; U56 CA92079/U56CA92081; the National Institutes of Health, Division of National Center on Minority and Health Disparities-sponsored (P60 MD000220) UCSD Comprehensive Research Center in Health Disparities; the UCSD Undergraduate Summer Research Program; the National Cancer Institute's UCSF/ UCLA Minority Training Program for Cancer Control Research grant R25 CA078583; and the National Institute of Aging's Medical Student Training in Aging Research grant T35AG026757.

The following newspapers have been critical to the success of this health journalism internship: San Diego Asian Journal, Philippine Mabuhay News, The Filipino Press, Pilipino Enquire, American Pacific Business Times, Asia, Asian Reader, Thoi Moi Magazine, Nguoi Viet Tu Do Magazine, San Diego California Examiner, Diario Veritas, La Prensa San Diego, El Sol de San Diego, Calexico Chronicle, La Jolla Light, Health Beat Magazine, Tao Tao San Diego, The San Diego Voice \& Viewpoint, and The African American News Link. The authors also wish to thank Nancy Stringer and Steve Benowitz of the UCSD Moores Cancer Center's Public Relations
Office for their supportive collaboration of the Health Journalism Internship.

Open Access This article is distributed under the terms of the Creative Commons Attribution Noncommercial License which permits any noncommercial use, distribution, and reproduction in any medium, provided the original author(s) and source are credited.

\section{References}

1. Hebert JR, Daguise VG, Hurley DM et al (2009) Mapping cancer mortality-to-incidence ratios to illustrate racial and sex disparities in a high-risk population. Cancer 115(11):2539-2552

2. Berry J, Bumpers K, Ogunlade V et al (2009) Examining racial disparities in colorectal cancer care. J Psychosoc Oncol 27(1):59-83

3. Terplan M, Smith EJ, Temkin SM (2009) Race in ovarian cancer treatment and survival: a systematic review with meta-analysis. Cancer Causes Control 20(7):1139-1150

4. Maxwell AE, Crespi CM (2009) Trends in colorectal cancer screening utilization among ethnic groups in California: are we closing the gap? Cancer Epidemiol Biomarkers Prev 18(3):752-759

5. Gomez SL, Tan S, Keegan TH, Clarke CA (2007) Disparities in mammographic screening for Asian women in California: a crosssectional analysis to identify meaningful groups for targeted intervention. BMC Cancer 7:201

6. Coughlin SS, Richards TB, Nasseri K et al (2008) Cervical cancer incidence in the United States in the US-Mexico border region, 1998-2003. Cancer 113(10 Suppl):2964-2973

7. Jerant AF, Fenton JJ, Franks P (2008) Determinants of racial/ ethnic colorectal cancer screening disparities. Arch Intern Med 168(12):1317-1324

8. Guadagnolo BA, Cina K, Helbig P et al (2009) Assessing cancer stage and screening disparities among Native American cancer patients. Public Health Rep 124(1):79-89

9. Jim MA, Perdue DG, Richardson LC et al (2008) Primary liver cancer incidence among American Indians and Alaska Natives, US, 1999-2004. Cancer 113(5 Suppl):1244-1255

10. Leistikow BN, Chen M, Tsodikov A (2006) Tobacco smoke overload and ethnic, state, gender, and temporal cancer mortality disparities in Asian-Americans and Pacific Islander-Americans. Prev Med 42(6):430-434

11. Willsie SK, Foreman MG (2006) Disparities in lung cancer: focus on Asian Americans and Pacific Islanders, American Indians and Alaska Natives, and Hispanics and Latinos. Clin Chest Med 27 (3):441-452, vi

12. Kaskowitz SR 3rd, Nakaji MC, Clark KL, Gunsauls DC, Sadler GR (2006) Bringing prostate cancer education to deaf men. Cancer Detect Prev 30(5):439-448

13. Samady W, Sadler GR, Nakaji M, Malcarne VL, Trybus R, Athale N (2008) Translation of the multidimensional health locus of control scales for users of American sign language. Public Health Nurs 25(5):480-489

14. Janz NK, Becker MH (1984) The health belief model: a decade later. Health Educ Q 11(1):1-47

15. Prochaska J, DiClemente C (1984) The transtheoretical approach: crossing traditional boundaries of therapy. Dow Jones-Irwin, Homewood

16. Bandura A (1986) Social foundations of thought and action: a social cognitive theory. Prentice.Hall, Englewood Cliffs

17. Fishbein M, Ajzen I (1975) Belief, attitude, intention, and behavior: an introduction to theory and research. Addison Wesley, Reading 
18. Ajzen I (1991) The theory of planned behavior. Org Behav Human Dec Proc 50(2):179

19. De Vries H, Dijkstra M, Kuhlman P (1988) Self-efficacy: the third factor besides attitude and subjective norm as a predictor of behavioural intentions. Health Educ Res 3(3):273-282

20. Andreasen A (1995) Marketing social change: changing behavior to promote health, social development, and the environment. Jossey-Bass, San Francisco

21. Kotler P, Zaltman G (1971) Social marketing: an approach to planned social change. J Mark 35(3):3-12

22. Bloom PN, Novelli WD (1981) Problems and challenges in social marketing. J Mark 45(2):79-88

23. Marcus BH, Owen N, Forsyth LH, Cavill NA, Fridinger F (1998) Physical activity interventions using mass media, print media, and information technology. Am J Prev Med 15(4):362-378

24. Kreuter MW, Strecher VJ, Glassman B (1999) One size does not fit all: the case for tailoring print materials. Ann Behav Med 21 (4):276-283

25. Jenkins CN, McPhee SJ, Bird JA et al (1999) Effect of a medialed education campaign on breast and cervical cancer screening among Vietnamese-American women. Prev Med 28(4):395-406

26. Trendwatching.com. Reports on global consumer trends. http:// trendwatching.com/briefing/. Accessed June, 2009.

27. Bly RW (1994) Targeted public relations: how to get thousands of dollars of free publicity for your product, service, organization, or Idea. Henry Holt \& Company, New York, NY

28. Sadler GR, Ko CM, Cohn JA, White M, Weldon RN, Wu P (2007) Breast cancer knowledge, attitudes, and screening behaviors among African American women: the Black cosmetologists promoting health program. BMC Public Health 7:57

29. Sadler GR, Thomas AG, Yen JY et al (2000) Breast cancer education program based in Asian grocery stores. J Cancer Educ 15(3):173-177

30. Ruiz MS, Marks G, Richardson JL (1992) Language acculturation and screening practices of elderly Hispanic women. The role of exposure to health-related information from the media. J Aging Health 4(2):268-281

31. Hu DJ, Keller R, Fleming D (1989) Communicating AIDS information to Hispanics: the importance of language and media preference. Am J Prev Med 5(4):196-200

32. Levinson JC (1999) Mastering guerrilla marketing: 100 profitproducing insights you can take to the bank. Houghton Mifflin Harcourt, New York, NY

33. Gladwell M (2000) The tipping point: how little things can make a big difference. Little, Brown \& Co, Boston, MA

34. Priest SH (2009) Doing media research: an introduction, 2nd edn. SAGE, Thousand Oaks, CA

35. Berger AA (1998) Media research techniques, 2nd edn. SAGE, Thousand Oaks
36. O'Sullivan T, Dutton B, Rayner P (2003) Studying the media: an introduction, 3rd edn. Arnold, London

37. Brawley EA (1995) Human services and the media: developing partnerships for change. Hardwood Academic Publishers, Newbury Park

38. Reah D (2002) The language of newspapers, 2nd edn. Routledge, London

39. Glanz K, Rimer BK, Lewis FM (2002) Health behavior and health education: theory, research, and practice, 3rd edn. Jossey-Bass, San Francisco

40. Curry SJ, Byers T, Hewitt ME (2003) Fulfilling the potential of cancer prevention and early detection, 2nd edn. National Academies Press, Washington, DC

41. Foster J (2005) Effective writing skills for public relations, 3rd edn. Kogan Page Publishers, London

42. Yudkin M (1994) 6 Steps to free publicity and dozens of other ways to win free media attention for you or your business. Plume, New York

43. Godin S, Gladwell M (2001) Unleashing the ideavirus: stop marketing at people! Turn your ideas into epidemics by helping your customers do the marketing for you. Hyperion, New York

44. Frost C (2002) Reporting for journalists. Routledge, London

45. Godin S, Peppers D (1999) Permission marketing: turning strangers into friends, and friends into customers. Simon and Schuster, New York

46. Wallack LM, Woodruff K, Dorfman L, Diaz I (1999) News for a change: an advocate's guide to working with the media. SAGE, Thousand Oaks

47. Keyes R (2003) The courage to write: how writers transcend fear, 2nd edn. Macmillan, New York

48. Hughes M (2005) Buzzmarketing: get people to talk about your stuff. Penguin Portfolio, New York

49. National Association of Science Writers. http://www.nasw.org/. Accessed 7 July 2009.

50. Newswise. http://www.newswise.com/. Accessed 7 July 2009.

51. Ries A, Ries L (2004) The fall of advertising and the rise of PR. Harper Collins, New York

52. Caburnay CA, Kreuter MW, Cameron G et al (2008) Black newspapers as a tool for cancer education in African American communities. Ethn Dis 18(4):488-495

53. Sun A, Zhang J, Tsoh J, Wong-Kim E, Chow E (2007) The effectiveness in utilizing Chinese media to promote breast health among Chinese women. J Health Commun 12(2):157-171

54. Jacoby BC (1996) Service-learning in higher education: concepts and practices, 1st edn. Jossey-Bass, San Francisco

55. Ottenritter NW (2004) Service learning, social justice, and campus health. J Am Coll Health 52(4):189-191

56. Duerksen SC, Mikail A, Tom L et al (2005) Health disparities and advertising content of women's magazines: a cross-sectional study. BMC Public Health 5:85 